\title{
The effect of phonemic processing on the retention of graphemic representations for words and nonwords
}

\author{
HOWARD S. HOCK, BARBARA THROCKMORTON, ELIZABETH WEBB, \\ and ALAN ROSENTHAL \\ Florida Atlantic University, Boca Raton, Florida 33431
}

\begin{abstract}
The three experiments reported in this study were each conducted in two phases. The first phase of Experiment 1 involved a same-different comparison task requiring "same" responses for both mixed-case (e.g., MAIN main) and pure-case (e.g., near near) pairs. This was followed by Phase 2, a surprise recognition test in which a graphemic effect on word retention was indicated by the superior recognition accuracy obtained for pure-case compared with mixed-case pairs. The first phases of Experiments 2 and 3 involved pronounceability and imageability judgment tasks, respectively. Graphemic retention was assessed by contrasting recognition accuracy for letter strings presented, during Phase 2, in their original Phase 1 case, with letter strings presented, during Phase 2, in a graphemically dissimilar new case. The experiments provided evidence that there was minimal retention of the graphemic representations from which the phonemic representations of words are generated and, further, that the locus of this effect is probably postlexical. Nonwords were recognized more accurately than words in all three experiments. The latter result was attributed to differences between nonwords and words in both graphemic retention and semantic distinctiveness.
\end{abstract}

The formation of a phonemic representation for a printed word requires at least some graphemic (visual) processing of the word. The phonemic representation could be generated by the application of grapheme-tophoneme translation rules to the individual letters or spelling units composing the word. Access to the lexicon, the memory store for words, would not be required. Phonemic representations might also be formed from whole-word graphemic representations, but in this case, graphemically mediated lexical access would be required before the phonemic representation of the word could be retrieved from memory. The research reported in this paper does not differentiate between the alternative ways that phonemic representations might be generated. Rather, it is concerned with the effect of forming a phonemic representation of a printed word on the retention of the graphemic representation from which the phonemic representation is generated. Since phonemic representations of printed words are effectively translations of visual/graphemic information into another medium, it was anticipated that phonemic processing would reduce the retrievability of graphemic representations. Of further interest was whether lexical access

Reprint requests should be sent to Howard Hock, Department of Psychology, Florida Atlantic University, Boca Raton, Florida 33431. The authors would like to thank Jack Columbo for his help in preparing the stimulus materials and Sue Williams, Cheryl Tromley, and Lynn Marshall for their help in conducting the experiments. We are also indebted to David Bjorklund, Howard Egeth, John Jonides, and Arthur Schulman for their careful reading of the manuscript. would result in differences in graphemic retention between words and nonwords.

Evidence for the short-term retention of graphemic representations has been obtained by Kirsner (1973), who showed that subjects' ability to recognize words presented up to $90 \mathrm{sec}$ earlier was enhanced when the words were printed in the same case as in their initial presentation, compared with when they were printed in a different case. Using a somewhat different paradigm, Scarborough, Cortese, and Scarborough (1977) have shown, for similarly short time intervals, that less time is required to decide whether or not a letter string is a word if the letter string is presented in the same case as in a previous presentation, compared with when it is presented in a different case. The retention of graphemic representations over longer periods of time has been extensively studied by Kolers. The most impressive of these studies (Kolers, 1976) is one indicating that subjects could reread inverted sentences that they had read 1 year earlier more rapidly than new inverted sentences. Other experiments (Kolers, 1973, 1974, 1975, 1976; Kolers \& Ostry, 1974) have studied subjects' ability to recognize previously read sentences. That is, subjects were required to discriminate between previously read and new sentences, the old sentences sometimes being printed in the same typographic format as in their initial reading (e.g., inverted-inverted) and sometimes being printed in a different typographic format (e.g., inverted-normal). The results of this contrast are somewhat mixed. Summarizing over the full set of Kolers' experiments, the general finding is that there 
is relatively little advantage in recognition when previously read sentences are re-presented in the same typographic format compared with a new typographic format. Kolers concludes that subjects retain information related to the pattern-analyzing operations they have performed on previously read sentences, but not literal copies of the sentences. This distinction, however, is somewhat clouded by Light and Berger's (1976) evidence that visual/graphemic representations of previously seen words are more abstract than literal copies but are nonetheless capable of influencing the recognition of previously seen words.

As indicated above, the research reported in this paper is concerned with the effect of phonemic processing on the retention of graphemic representations of words. While related questions involving the effect of initial processing on the nature of the memory trace have been raised in studies based on the "levels-ofprocessing" framework (Craik \& Lockhart, 1972), there are a number of reasons for doubting the usefulness of these studies with regard to the more specific question of whether phonemic processing affects graphemic retention (for more general critiques of this approach, see Baddeley, 1978; Eysenck, 1978). Theoretically, the levels-of-processing framework treats graphemic and phonemic processes as sequential steps on the way to greater "depths" of processing. Thus, graphemic precedes phonemic, which in turn precedes semantic processing. Although at least some graphemic processing must always precede the formation of phonemic representations for words, numerous studies have provided evidence against a purely serial model. These studies, which include lexical decision tasks (e.g., Meyer, Schvaneveldt, \& Ruddy, 1974; Shulman, Hornak, \& Sanders, 1978), reading tasks (e.g., Baron, 1977; Baron \& Strawson, 1976), and same-different comparison tasks (e.g., Baron, 1978; Pollatsek, Well, \& Schindler, 1975), have led investigators to conclude that parallel graphemic and phonemic channels emerge prior to lexical access and the retrieval of the semantic content of the word. Focusing as it does on sequential processing, the levels-of-processing approach does not readily incorporate parallel processing models.

The levels-of-processing framework has also been subject to empirical criticism. Although it has been claimed that processing at the structural (graphemic) level leads to poorer retention than processing at the phonemic level (e.g., Craik \& Tulving, 1975), subsequent research has indicated that memory performance depends, to a large extent, on whether the information stored during the initial orienting task corresponds with the information required by the subsequent memory test (e.g., Morris, Bransford, \& Franks, 1977). Furthermore, the evidence suggesting that phonemic processing results in better retention than graphemic processing does not provide any indication of whether or not graphemic representations are retained when phonemic representations are generated for printed words. To this end, three experiments were performed, each of which was composed of two phases. Depending on the experiment, the first phase involved same-different, pronounceability, or imageability judgments for words and nonwords. This was followed in each experiment by Phase 2, a surprise forced-choice recognition test in which subjects were required to discriminate between items presented during Phase 1 and items that were not presented during Phase 1. Experiment 1 provided evidence of a graphemic effect on the recognition of words. The results of Experiment 2 indicated that when subjects were required to form phonemic representations for words and nonwords, a graphemic effect on recognition accuracy was obtained for the nonwords, but not for the words. This provided evidence that phonemic processing results in minimal retention of the graphemic representations of words and, further, that the locus of this effect is probably postlexical. Experiment 3, in addition to demonstrating that subjects can retain graphemic representations of words when phonemic processing is not required, showed that the results of Experiment 2 were not due to differences in graphemic distinctiveness between words and nonwords.

\section{EXPERIMENT 1}

The purpose of this experiment was to provide evidence of a graphemic effect on the recognition of previously seen words, with retention intervals longer than those used in Kirsner's (1973) and Scarborough et al.'s (1977) experiments and materials less complex than the sentences used in Kolers' (e.g., 1976) research. Phase 1 of the experiment involved a same-different comparison task in which subjects judged whether pairs of simultaneously presented, orthographically regular words were the same or different. Some of the word pairs were printed in mixed case (e.g., DIAL dial), whereas other word pairs were printed in pure case (e.g., BOOK BOOK). Evidence for a graphemic effect on retention would be obtained if words presented in graphemically identical, pure-case "same" pairs during Phase 1 were recognized (i.e., discriminated from words that were not presented during Phase 1) more accurately than words presented in graphemically nonidentical, mixed-case "same" pairs during Phase 1. Also presented in Phase 1 were pairs of pure-case nonwords (e.g., ORVE ORVE). The word-nonword contrast was introduced in order to determine whether the presence or absence of lexical entries for items would affect the accuracy with which they were subsequently recognized.

\section{Method}

As indicated above, the experiment was conducted in two phases. The first phase comprised a same-different reaction time task involving pairs of letter strings. It was followed immediately by Phase 2, a surprise forced-choice recognition test in which subjects were required to discriminate between previously seen letter strings (from Phase 1) and new letter strings. Since there 
was no instruction for the subjects to remember the items presented during Phase 1, Phase 2 effectively involved a test of incidental learning.

Stimuli. The stimuli used in the experiment were pairs of simultaneously presented letter strings, each composed of four letters. The letter strings varied with respect to whether they were (1) the same or different, (2) typed in uppercase or lowercase format, and (3) common words or pronounceable nonwords. Slides were prepared by photographing black letters typed (Prestige Elite 72) on a white background. When backprojected onto a translucent screen, each four-letter string subtended a visual angle of $1.2 \mathrm{deg}$. The visual angle between the centers of the two letter strings, which were presented alongside each other, was $2.5 \mathrm{deg}$.

For half the stimuli, the two letter strings in each pair were the same; for the other half, they were different. When the letter strings were words, "same" pairs were either pure case (e.g. love love, SORT SORT) or mixed case (e.g., NOTE note, next NEXT). "Different" word pairs were also either pure case (e.g., SLIM SKIN) or mixed case (e.g., rang MANY). For mixedcase stimuli, each case appeared equally often in the left and right positions of each stimulus pair. For pure-case stimuli, lowercase and uppercase pairs were presented with equal frequency. The mixed-case stimuli consisted entirely of words. The pure-case stimuli comprised pairs of words and pairs of pronounceable nonwords. The nonwords were generated by permuting the order of the letters of the words in the pure-case stimuli. For example, word order in the stimulus MOVE SAVE was permuted to produce the stimulus MEVO SEVA. The same permutation was always applied to both words in each stimulus pair (the second and fourth letter positions in the above example). Different combinations of all four letter positions were permuted in producing the full set of nonwords. For word pairs (pure case and mixed case) and nonword pairs (pure case only), the members of "different" pairs always differed by two letters. The letter positions in each pair that were different varied from stimulus to stimulus. Thus, "tall TOLD" differed in Positions 2 and 4, whereas "rust vest" differed in Positions 1 and 2. For "different" pairs involving only lowercase letters, the two letter strings always had the same global shape (e.g., tray trip).

All the subjects in the experiment were presented a total of 120 stimuli during Phase 1 . Forty stimuli were pairs of common words in mixed case (20 same, 20 different), 40 were pairs of common words in pure case ( 20 same, 20 different), and 40 were pairs of pronounceable nonwords in pure case ( 20 same, 20 different). The full set of Phase 1 stimuli are listed in Appendix A. Each letter string used in Phase 1 appeared in only one stimulus presentation. The order of stimuli from the various stimulus conditions was randomized within four blocks of 30 trials, and the order of blocks was counterbalanced (Latin square) between groups of subjects. An additional 30 practice trials were presented prior to the 120 experimental trials. The practice trials were composed of stimuli from all the conditions presented in the experimental trials, but using letter strings that were not used in either Phase 1 or Phase 2.

Phase 2 of the experiment involved a forced-choice recognition test. Each of the Phase 1 letter strings (original) was paired with a new four-letter string (distractor). For half the recognition stimuli, the original was presented to the left of the distractor, and for the other half, to the right. The full set of distractors used in Phase 2 are presented in Appendix B. There were 180 stimulus pairs in the recognition test. Sixty pairs included originals that had appeared in "same" stimuli during Phase 1 , and 120 pairs included originals that appeared in "different" stimuli during Phase 1 (there were necessarily twice as many letter strings in the "different" as in the "same" condition of Phase 1). The recognition stimuli were presented in random order on two $8.5 \times 11$ in. sheets of paper (30 pairs/ column, 3 columns/sheet). The originals were presented in the same case as in Phase 1, and each distractor was presented in the same case as the original with which it was paired. Originals that were common words were paired with distractors that were also common words; originais that were pronounceable nonwords were paired with distractors that were also pronounceable nonwords. Most of the nonwords used as distractors were permutations of words that were also used as distractors. ${ }^{1}$ The original/ distractor pairs were highly dissimilar with respect to spelling, pronunciation, and meaning.

Procedure. The stimuli presented during Phase 1 were backprojected onto a translucent screen via a Carousel projector. An electronic shutter limited the exposure of each stimulus to a duration of $1 \mathrm{sec}$. Subjects were instructed to respond "same," by pressing a button with a finger of their preferred hand, whenever the pair of letter strings had the same identity, even if they differed in case. When the letter strings were different in identity, subjects were not to respond. Subjects were instructed to respond as quickly as possible, within the context of keeping their errors to a minimum. If a response did not occur within the 1 -sec stimulus presentation, it was counted as an error of omission. As indicated above, there were no memory instructions presented during Phase 1.

Phase 2 comprised a forced-choice recognition test. Pairs of letter strings (originals and distractors) were presented on two sheets of paper, and subjects were instructed to circle the letter string in each pair that they had seen during the preceding portion of the experiment. They were required to guess if they were unsure of the correct response. There was no time limit for the completion of Phase 2.

Subjects. Thirty-two unpaid undergraduate students at Florida Atlantic University voluntarily participated in this experiment, which lasted about $30 \mathrm{~min}$. None of the subjects indicated, when they were asked at the conclusion of the experiment, that they anticipated a memory test.

\section{Results}

The results for both phases of Experiment 1 are presented in Table 1. An analysis of variance on mean "same" reaction times for Phase 1 indicated that the effect of stimulus type (mixed-case words, pure-case words, pure-case nonwords) was significant $[\mathrm{F}(2,62)=$ 215.67, $\mathrm{p}<.005, \mathrm{MSe}=411]$. Newman-Keuls tests indicated that "same" reaction times were significantly slower for the mixed-case words than for pure-case words and were also significantly slower for the purecase nonwords than for the pure-case words $(p<.01)$ (this result has been obtained previously by Barron \&

Table 1

Experiment 1: Mean Reaction Times (in Milliseconds) for Correct "Same" Responses, Percent Errors of Omission and Commission (Phase 1), and Percent Recognition Accuracy (Phase 2)

\begin{tabular}{|c|c|c|c|c|c|c|}
\hline & \multicolumn{4}{|c|}{ Words } & \multirow{2}{*}{\multicolumn{2}{|c|}{$\begin{array}{l}\text { Nonwords } \\
\text { (Pure Case) }\end{array}$}} \\
\hline & \multicolumn{2}{|c|}{ Mixed Case } & \multicolumn{2}{|c|}{ Pure Case } & & \\
\hline & Mean & SE & Mean & SE & Mean & SE \\
\hline & \multicolumn{6}{|c|}{ Phase 1: Same-Different Task } \\
\hline "Same” RT & 584.0 & & 520.0 & & 624.0 & \\
\hline Commissions & 2.7 & & 3.4 & & 2.5 & \\
\hline \multirow[t]{2}{*}{ Omissions } & 3.3 & & .5 & & 2.0 & \\
\hline & \multicolumn{6}{|c|}{ Phase 2: Recognition Accuracy } \\
\hline "Sames" , & 62.6 & 2.1 & 68.3 & 2.6 & 76.0 & 2.1 \\
\hline "Differents" & 63.9 & 1.6 & 63.9 & 1.8 & 62.5 & 1.8 \\
\hline
\end{tabular}

Note-Recognition accuracy is reported for letter strings that appeared in either "same" or "different" pairs during Phase 1. 
Pittinger, 1974, and others). There was no indication that the above differences in reaction times were the result of differential speed/accuracy criteria. Error rates, however, were too low to draw any firm conclusions in this regard.

An examination of the results for Phase 2 indicated that differences in recognition accuracy between the three stimulus types were obtained only for letter strings appearing in "same" pairs during Phase 1. An analysis of variance on percent recognition accuracy in Phase 2 indicated that the interaction between same-different and stimulus type (mixed-case words, pure-case words, pure-case nonwords) was significant $[\mathrm{F}(2,62)=11.41$, $\mathrm{p}<.005, \mathrm{MSe}=80]$. Tests of simple effects indicated that the effect of stimulus type on Phase 2 recognition accuracy was significant for letter strings that had appeared in "same" pairs during Phase $1[F(2,124)=$ $18.01, \mathrm{p}<.001, \mathrm{MSe}=82$ ] but was not significant for letter strings that had appeared in "different" pairs during Phase $1[\mathrm{~F}(2,124<1.0, \mathrm{MSe}=82]$. Finally, Newman-Keuls tests for the letter strings from the "same" condition indicated that (1) the type of match during Phase 1 affected the accuracy of word recognition in Phase 2 (pure-case words were recognized significantly more accurately than mixed-case words; $p<.01$ ) and (2) the type of letter string affected recognition accuracy (pure-case nonwords were recognized significantly more accurately than pure-case words; $p<.01$ ).

The difference in recognition accuracy between words from the pure-case and mixed-case conditions could not be attributed to differences in processing time. If processing time were a significant factor, words in the slower, mixed-case condition would have been recognized more accurately than words in the faster, pure-case condition. The actual recognition performance for the words was opposite in direction from performance differences predicted by differences in processing time. In a similar vein, a supplementary analysis indicated that the relatively high recognition accuracy obtained for the nonwords in Phase 2 was not due to their having the slowest "same" responses during Phase 1. This analysis was performed for a subset of 10 subjects selected on the basis of the similarity of their Phase 1 "same" reaction times for the mixed-case words and the pure-case nonwords. The mean "same" reaction times of these selected subjects were virtually identical in these conditions ( $600 \mathrm{msec}$ for mixed-case words and $604 \mathrm{msec}$ for the pure-case nonwords). Nonetheless, a substantial difference in recognition accuracy was still obtained for the selected subjects: $61.5 \%$ correct for the "same" mixed-case words, as compared with $73.0 \%$ correct for the "same" pure-case nonwords.

An additional analysis was concerned with whether the results described above were generalizable over stimulus materials as well as subjects. This involved the use of the different letter strings rather than subjects as the random variable in the analysis of variance. The results of this analysis again indicated that the interaction between stimulus type and same-different was significant $[F(2,174)=3.53, p<.05$, MSe $=202]$. Tests of simple effects again indicated that the effect of stimulus type was significant for letter strings from "same" pairs $[F(2,174)=4.34, p<.05, \mathrm{MSe}=202]$ but was not significant for letter strings from "different" pairs $[F(2,174)<1.0, M S e=202]$. For Newman-Keuls tests on letter strings from "same" pairs, however, the difference between mixed-case and pure-case words fell short of significance at the .05 level, as did the difference between the pure-case words and the pure-case nonwords. Finally, an analysis was performed that separated the 20 pure-case nonwords into two sets comprising orthographically regular (9) and irregular (11) nonwords. ${ }^{2}$ The recognition data for these sets indicated virtually no difference between them. That is, there was no apparent effect of orthographic regularity on recognition accuracy for the nonwords. The wordnonword difference was therefore obtained even when the comparison was restricted to nonwords that were classified as orthographically regular.

\section{Discussion}

The results of the Phase 2 recognition test indicated that words presented in the "same" pure-case condition during Phase 1 were recognized more accurately than words presented in the "same" mixed-case condition during Phase 1. This difference could not be attributed to longer processing time being required for the "same" pure-case condition. The results for Phase 1 indicated that "same" responses were faster for the pure-case than for the mixed-case word pairs, not slower. Rather than processing time, the tendency for the "same" pure-case words to be recognized more accurately than the "same" mixed-case words could be attributed to differences in graphemic similarity between them: The "same" pure-case pairs were graphemically identical, whereas the "same" mixed-case pairs were graphemically nonidentical. This conclusion was also consistent with the evidence that recognition accuracy was virtually identical for words from mixed-case and pure-case "different" pairs. Both types of "different" pair were graphemically dissimilar.

There are several potential explanations for the apparent effect of graphemic similarity on recognition accuracy for words from "same" pairs" (1) The graphemic identity of pure-case pairs could have increased attention to the graphemic characteristics of purecase compared with graphemically nonidentical, mixedcase pairs. (2) "Same" responses for mixed-case but not for pure-case pairs were mediated by phonemic representations of the words. According to the hypothesis posed in the introduction to this paper, phonemic processing could have resulted in reduced attention to the graphemic representations of words from mixed. case "same" pairs. (3) Graphemic repetition could have increased the "strength" of the memory trace for purecase as compared with mixed-case pairs. ${ }^{3}$ Although the results of this experiment do not differentiate among these three alternative explanations, they do provide 
evidence of a graphemic effect on retention for time intervals of up to $20 \mathrm{~min}$, with materials considerably less complex than Kolers' (e.g., 1976) sentences. Although Kolers' stimuli are obviously more relevant to the problem of reading skill, the results of this experiment indicated that a graphemic effect on the retention of words could be obtained with simplified materials that were well suited for the purpose of the next experiment, which provided a direct test of the effect of phonemic processing on the retention of graphemic representations.

Before proceeding to the next experiment, it should be noted that the nonwords were recognized more accurately than the words, even when nonwords that were orthographically irregular were excluded from the comparison. This result was analogous to previous evidence that novel but physically possible scenes are recognized more accurately than familiar scenes (Hock, Romanski, Galie, \& Williams, 1978). While there are a number of possible explanations for the superior recog. nition of the nonwords, the most likely is that the nonwords, being novel, were more distinctive than the common words. In processing a word during Phase 1 (i.e., an "original" in the Phase 2 recognition test), a semantic relationship could be activated with a word that is a member of the "distractor" set during Phase 2 . This potential for semantic confusability between originals and distractors is minimized for nonwords. Being essentially meaningless, there was little likelihood of semantic confusion between original and distractor nonwords in the recognition test. The absence of wordnonword difference in recognition accuracy for "different" pairs is not as readily explained. One possibility is that "different" pairs were compared on a letter-byletter basis, so that semantic information was not retrieved for words from "different" pairs. There was, however, no empirical evidence to either support or refute this conjecture.

\section{EXPERIMENT 2}

Based on the evidence that graphemic effects on word recognition could be obtained with the experimental paradigm used in Experiment 1, we could determine in this experiment, which used the same stimulus materials, whether a Phase 1 task that explicitly required phonemic processing of printed words would affect the retention of graphemic representations for the words. The Phase 1 task in this experiment, instead of involving samedifferent comparison, required that subjects judge the pronounceability of the words and nonwords. This experiment also differed from Experiment 1 with respect to the assessment of graphemic effects on recognition accuracy. In Experiment 1, graphemic effects were inferred from the difference in recognition accuracy between the "same" pure-case and "same" mixed-case conditions. In this experiment, graphemic effects were also tested by introducing a case-change manipulation into the recognition test. That is, for half the stimuli in the Phase 2 recognition test, the letter strings were presented in the same case as in Phase 1 (they were graphemically identical). For the other half of the stimuli in the Phase 2 recognition test, the letter strings were presented in a case different from that in Phase 1 (they were graphemically nonidentical). It was anticipated that the results of this case-change manipulation would provide a direct test of whether graphemic memory representations influenced recognition performance, since changing the case would reduce the utility of the graphemic representations and thereby reduce recognition accuracy.

\section{Method}

The stimuli, procedure, and design for this experiment differed from those of Experiment 1 in only two respects. In Experiment 1, the Phase 1 task involved the same-different comparison of the letter strings. In this experiment, pairs of letter strings were presented for $1 \mathrm{sec}$ each in the same sequence of same-different pairings used in Experiment 1, but samedifferent judgments were not required. Instead, subjects were instructed to read both letter strings in every same-different pairing and rate each letter string for its pronounceability (on a 5-point scale: 5 = easy, $1=$ difficult) ${ }^{4}$ As in Experiment 1, subjects were given no indication that there would be a subsequent memory test. The second difference from the design of Experiment 1 involved the case of the letter strings presented in the Phase 2 recognition test. For half the Phase 1 letter strings, equally distributed across the various stimulus conditions, the case was changed when the letter strings were presented for recognition in Phase 2 (except for the words in the mixed-case "same" condition). The case of the distractors with which these originals were paired was also changed so that they remained in the same case as the originals. For the letter strings that were changed, half went from lowercase to uppercase, and half went from uppercase to lowercase. The set of letter strings for which the Phase 1 case was changed and the set that remained in the Phase 1 case were counterbalanced across subjects.

Forty eight undergraduate students at Florida Atlantic University voluntarily participated in this experiment without pay. The experimental session lasted about $30 \mathrm{~min}$. None of the subjects indicated, when they were asked at the conclusion of the experiment, that they anticipated a memory test.

\section{Results}

The results of the experiment are presented in Table 2 . An examination of subjects' pronounceability ratings during Phase 1 indicated that the nonwords were judged to be somewhat more difficult to pronounce than the words. Although this difference may reflect true differences in ease of pronunciation, it is also possible that subjects' viewed the experimental procedure as implicitly demanding use of at least several points on the rating scale. The word-nonword distinction may have been the basis for subjects' meeting this implicit demand characteristic of the rating task.

The results of the Phase 2 recognition test provided two kinds of evidence that graphemic memory representations had little influence on the recognition of words. One kind of evidence came from the recognition data obtained for words that were tested in their original Phase 1 case (the old-case condition). Unlike the results obtained in Experiment 1, there was little difference in recognition accuracy between words presented in the 
Table 2

Experiment 2: Mean Pronounceability Ratings (Phase 1) and Percent Recognition Accuracy (Phase 2)

\begin{tabular}{|c|c|c|c|c|c|c|c|c|c|c|c|c|}
\hline \multirow[b]{4}{*}{ Case } & \multirow{3}{*}{\multicolumn{2}{|c|}{$\begin{array}{c}\text { Phase 1: Pronounce- } \\
\text { ability Ratings }\end{array}$}} & \multicolumn{10}{|c|}{ Phase 2: Recognition Accuracy } \\
\hline & & & \multicolumn{5}{|c|}{ "Sames" } & \multicolumn{5}{|c|}{ "Differents" } \\
\hline & & & \multicolumn{2}{|c|}{ Old Case (O) } & \multicolumn{2}{|c|}{ New Case $(\mathrm{N})$} & \multirow[b]{2}{*}{$\mathrm{O}-\mathrm{N}$} & \multicolumn{2}{|c|}{ Old Case $(0)$} & \multicolumn{2}{|c|}{ New Case $(\mathrm{N})$} & \multirow[b]{2}{*}{$\mathrm{O}-\mathrm{N}$} \\
\hline & Pairs & ent" Pairs & Mean & $\mathrm{SE}$ & Mean & SE & & Mean & SE & Mean & $\mathrm{SE}$ & \\
\hline & \multicolumn{12}{|c|}{ Words } \\
\hline Mixed & 3.7 & 3.5 & 72.6 & 1.8 & & & & 72.1 & 1.8 & 73.2 & 1.9 & -1.1 \\
\hline Pure & 3.7 & 3.5 & 75.2 & 2.4 & 76.4 & 2.3 & -1.2 & 69.5 & 1.9 & 70.1 & 2.2 & -.6 \\
\hline & \multicolumn{12}{|c|}{ Nonwords } \\
\hline Pure & 2.7 & 2.4 & 89.4 & 1.6 & 82.7 & 2.0 & 6.7 & 77.1 & 1.8 & 74.6 & 1.8 & 2.5 \\
\hline
\end{tabular}

Note-Pronounceability ratings are based on a 5-point scale: $5=$ easy, $1=$ difficult. Recognition accuracy is reported for letter strings that appeared in either "same" or "different" pairs during Phase 1.

"same" pure-case condition during Phase 1 (75.2\% correct) and words presented in the "same" mixed-case condition during Phase 1 ( $72.6 \%$ correct). The small difference, which was not statistically significant $[F(1,47)=1.23, p>.05, \mathrm{MSe}=133\}$, indicated that whatever effects graphemic similarity might have had on word recognition were not evident in the results of this experiment. If graphemic similarity had been a factor in this experiment, the graphemically identical word pairs in the "same" pure-case condition would have been recognized significantly more accurately than the graphemically nonidentical word pairs in the "same" mixed-case condition.

The primary indication that there was minimal retention of graphemic representations for words came from the evidence that changing the Phase 1 case of the letter strings when they were presented for recognition in Phase 2 affected recognition accuracy for nonwords, but not for words. If subjects had retained graphemic representations of the words, changing the case during testing would have reduced the effectiveness of the representations and, thereby, reduced recognition accuracy. An analysis of variance performed on percent recognition accuracy involved four factors: type of letter string (word vs. nonword), type of pair ("same" vs. "different"), whether or not the Phase 1 case of the letter strings was changed in Phase 2 (old case vs. new case), and a between-groups factor involving the counterbalancing of letter strings assigned to the old-case and new-case conditions. The mixed-case word pairs were omitted from this analysis because they comprised both uppercase and lowercase pairs, precluding the introduction of a new-case condition for these stimuli in Phase 2. The analysis of variance indicated that the interaction between the type of letter string (word vs. nonword) and the effect of letter strings appearing in "same" vs. "different" pairs in Phase 1 fell just short of significance at the .05 level $[F(1,46)=3.64, p=.06, \mathrm{MSe}=$ $112] .5$ Tests of simple effects indicated that nonwords were recognized significantly more accurately than words, regardless of whether they were presented in "same" or "different" pairs during Phase $1[F(1,92)=$
31.79 and $F(1,92)=11.30$, respectively; $p<.005$, $\mathrm{MSe}=157$, in both cases $]$.

As described above, changing the Phase 1 case of the letter string during the Phase 2 recognition test affected recognition accuracy for nonwords, but not for words. The interaction between the type of letter string (word vs. nonword) and whether or not the Phase 1 case of the letter string was changed in Phase 2 (old case vs. new case) was significant $[F(1,46)=5.40, p<.025, \mathrm{MSe}=$ 137]. Tests of simple effects indicated that the effect of changing to a new case significantly reduced recognition accuracy for the nonwords $[F(1,92)=9.04, p<.005$, $\mathrm{MSe}=113]$, but not for the words $[F(1,92)<1.0$, $\mathrm{MSe}=113]$. The triple interaction among type of letter string, whether or not the Phase 1 case of the letter string was changed in Phase 2, and whether the letter string came from a "same" or "different" pair in Phase 1 was not significant $[\mathrm{F}(1,46)=1.12, \mathrm{p}>.05, \mathrm{MSe}=120]$.

In order to determine whether these results were generalizable over the stimuli used in the experiment, the set of letter strings (from both "same" and "different" pairs) rather than subjects was used as the random variable in the analysis of variance. ${ }^{6}$ The interaction between the type of letter string (word vs. nonword) and whether or not the Phase 1 case of the letter strings was changed (old case vs. new case) in the Phase 2 recognition test was again significant $[F(1,56)=4.48$, $\mathrm{p}<.05$, MSe $=81]$. Tests of simple effects again indicated that the effect of case change was significant for the nonwords $[\mathrm{F}(1,112)=5.29, \mathrm{p}<.05, \mathrm{MSe}=87]$ but was not significant for the words $[F(1,112)<1.0$, $\mathrm{MSe}=87]$. The differential effect of case change on recognition accuracy for words vs. nonwords was thus generalizable over both subjects and stimulus items. Further analyses for the nonwords indicated that (1) there was virtually no difference between the 9 nonwords classified as orthographically regular and the 11 nonwords classified as orthographically irregular with regard to either the effect of changing case on recognition accuracy or overall recognition performance and (2) the pronounceability of the nonwords (from Phase 1) was not correlated with either the effect of 
case change $(r=-.11, p>.05)$ or overall recognition accuracy $(\mathrm{r}=.13, \mathrm{p}>.05)$. The latter correlations indicated that the graphemic effects obtained for the nonwords were not influenced by differences in their pronounceability.

\section{Discussion}

The results for the nonwords indicated that they were recognized more accurately in Phase 2 when they were presented in their original Phase 1 case than when they were presented in a new case. This evidence for a graphemic effect on the recognition of nonwords demonstrated that the case-change manipulation introduced in this experiment provided a sensitive index of graphemic memory representation. The graphemic effect obtained for the nonwords was important for another reason. It showed that the failure to obtain a graphemic effect for the words was not due to selective attention to the phonemic representations subjects had to form in order to perform the Phase 1 pronunciation task. If taskrelevant selective attention was responsible for the absence of graphemic retention in this experiment, it would have also eliminated the graphemic effect that was obtained for the nonwords. As a result, it could be concluded that graphemic representations formed in the course of generating phonemic representations for words (as required by the pronounceability rating task) had no discernible effect on the subsequent recognition of the words. Furthermore, the graphemic effect on recognition accuracy was obtained for nonwords, whether they were orthographically regular or not, suggesting that selective effects occurring subsequent to lexical access were responsible for the absence of a graphemic influence on the recognition of the words. Finally, subjects' tendency to retain graphemic representations for nonwords, but not for words, appeared to be a contributing factor in the word-nonword difference in recognition accuracy. As in Experiment 1, the nonwords were recognized more accurately than the words, but the size of the word-nonword difference was diminished when the letter strings were presented in a new case.

\section{EXPERIMENT 3}

The results of Experiment 2 suggested that the difference in graphemic retention between words and nonwords was due to the use of a Phase 1 task requiring the formation of phonemic representations. Although differences in orthographic regularity did not affect the recognition of previously seen nonwords in Experiment 2, Zechmeister (1972) has shown that orthographic distinctiveness can affect the recognition of previously seen words. Also, Hunt and Elliott (1980) have shown that orthographic distinctiveness affects word recall because of the visual/graphemic distinctiveness of orthographically irregular words. The purpose of this experiment was to determine, independent of estimates of orthographic regularity, whether differ- ences in graphemic distinctivess between the words and nonwords could have been responsible for the results of Experiment 2. That is, the absence of a graphemic effect for the words in Experiment 2 may have been due to the "original" words from Phase 1 being more graphemically confusable with the "distractor" words presented in the Phase 2 recognition test than was the case for the "original" and "distractor" nonwords. If this argument is correct, the case-change effect should remain greater for the nonwords than for the words, even when a task requiring graphemic representation is used in Phase 1. If, however, the absence of a casechange effect for the words in Experiment 2 was specifically due to the use of a Phase 1 task requiring phonemic representation, graphemic effects of the same magnitude should be obtained for both words and nonwords when a graphemic task is used in Phase 1.

Also of interest was the word-nonword difference in recognition accuracy. The results of Experiment 2 suggested that differences in graphemic representation contributed to the word-nonword difference. Whether or not a residual word-nonword effect would be obtained when the Phase 1 task directed attention to the graphemic characteristics of the words could be determined from the results of the present experiment.

\section{Method}

The stimuli, procedure, and design for this experiment were identical to those of Experiment 2 in all respects but one. During Phase 1, the letter strings were presented in the identical sequence of same-different pairings used in Experiments 1 and 2, but as in Experiment 2, same-different judgments were not required. In this experiment, the Phase 1 task directed attention to the graphemic characteristics of letter strings. Subjects were instructed to form a visual image for each pair of letter strings and to maintain that image for $3 \mathrm{sec}$ after the termination of the 1-sec presentation of the letter strings. After every presentation, subjects were required to rate the imageability of each pair of letter strings (on a 5-point scale: 5 = easy, $1=$ difficult). The instructions emphasized that the subjects should form images of the letter strings themselves, not concepts to which they might refer. As in the previous experiments, subjects were given no indication that there would be a subsequent memory test. Thirty-two undergraduate students at Florida Atlantic University voluntarily participated in this experiment, for which they were each paid $\$ 2$. Once again, none of the subjects indicated, when they were asked at the conclusion of the experiment, that they anticipated a memory test.

\section{Results}

The results of the experiment are presented in Table 3. Subjects' ratings of imageability were higher for words than for nonwords and higher for "same" pairs than for "different" pairs. Although these differences might represent true differences in imageability, they could also be the result of demand characteristics implicit in the use of the rating scale. As discussed for the pronounceability ratings of the previous experiment, the same-different and word-nonword distinctions may have been the basis for subjects' meeting the implicit demand that they utilize at least several points on the rating scale.

The results of the Phase 2 recognition test provided 
Table 3

Experiment 3: Mean Imageability Ratings (Phase 1) and Percent Recognition Accuracy (Phase 2)

\begin{tabular}{|c|c|c|c|c|c|c|c|c|c|c|c|c|}
\hline \multirow[b]{4}{*}{ Case } & \multirow{3}{*}{\multicolumn{2}{|c|}{$\begin{array}{l}\text { Phase 1: Image- } \\
\text { ability Ratings }\end{array}$}} & \multicolumn{10}{|c|}{ Phase 2: Recognition Accuracy } \\
\hline & & & \multicolumn{5}{|c|}{ "Sames" } & \multicolumn{5}{|c|}{ "Differents" } \\
\hline & & \multirow{2}{*}{$\begin{array}{l}\text { "Differ- } \\
\text { ent" Pairs }\end{array}$} & \multicolumn{2}{|c|}{ Old Case $(0)$} & \multicolumn{2}{|c|}{ New Case $(\mathrm{N})$} & \multirow[b]{2}{*}{$\mathrm{O}-\mathrm{N}$} & \multicolumn{2}{|c|}{ Old Case (0) } & \multicolumn{2}{|c|}{ New Case (N) } & \multirow[b]{2}{*}{$\mathrm{O}-\mathrm{N}$} \\
\hline & $\begin{array}{l}\text { "Same" } \\
\text { Pairs }\end{array}$ & & Mean & SE & Mean & SE & & Mean & SE & Mean & SE & \\
\hline & \multicolumn{12}{|c|}{ Words } \\
\hline Mixed & 4.7 & 4.2 & 70.6 & 2.2 & & & & 70.5 & 2.5 & 70.2 & 2.0 & .3 \\
\hline \multirow[t]{2}{*}{ Pure } & 4.9 & 4.4 & 77.2 & 2.5 & 66.8 & 3.6 & 10.4 & 69.7 & 2.4 & 68.1 & 2.4 & 1.6 \\
\hline & \multicolumn{12}{|c|}{ Nonwords } \\
\hline Pure & 4.4 & 3.4 & 86.2 & 1.9 & 79.4 & 2.5 & 6.8 & 70.8 & 1.8 & 70.2 & 1.9 & .6 \\
\hline
\end{tabular}

Note-Imageability ratings are based on a 5-point scale: $5=$ easy, $1=$ difficult. Recognition accuracy is reported for letter strings that appeared in either "same" or "different" pairs during Phase 1.

two kinds of evidence for the hypothesized graphemic effect on recognition accuracy for words. As in Experiment 1 , words tested in their original, Phase 1 case (the old-case condition) were recognized more accurately when they had been presented in the "same" pure-case condition during Phase 1 (77.2\% correct) than when they had been presented in the "same" mixed-case condition during Phase 1 (70.6\% correct). This difference, which could be attributed to the graphemic identity of the "same" pure-case pairs, was statistically significant $[\mathrm{F}(1,31)=4.80, \mathrm{p}<.05, \mathrm{MSe}=143]$. However, this advantage in recognition for words from purecase "same" pairs was eliminated when the case of the pure-case "sames" was changed in the recognition test. The difference in recognition accuracy between words from mixed-case and pure-case "same" pairs could therefore be attributed to differences between them in the retention of graphemic memory representations for the words.

Further evidence for a graphemic influence on word and nonword recognition came from the substantial effect of case change (old case vs. new case) on recognition accuracy. The case-change effect, however, was limited to letter strings appearing in the "same" pairs during Phase 1. An analysis of variance on percent recognition accuracy (restricted, as in Experiment 2, to letter strings from the pure-case conditions) indicated that the Case (old-new) by Same-Different interaction was significant $[F(1,30)=4.14, p=.05, \mathrm{MSe}=175]$. Tests of simple effects indicated that for letter strings that appeared in "same" pairs during Phase 1, those tested in their old case were recognized significantly more accurately than those tested in a new case $[F(1,60)$ $=13.11, p<.001, \mathrm{MSe}=161]$. For letter strings that appeared in "different" pairs during Phase 1 , the effect of case (old vs. new) was not significant $[F(1,60)<1.0$, $\mathrm{MSe}=161]$. Thus, there was evidence of a graphemic effect on recognition accuracy for letter strings presented in "same" pairs during Phase 1 , but no graphemic effect for letter strings presented in "different" pairs during Phase 1 . Nonwords were again recognized more accurately than words, but only for letter strings from "same" pairs. The Word-Nonword by Same-Different interaction was significant $[\mathrm{F}(1,30)=15.08, \mathrm{p}<.001$, $\mathrm{MSe}=90]$, and tests of simple effects indicated that, for letter strings from "same" pairs, nonwords were recognized significantly more accurately than words $[\mathrm{F}(1,60)=28.06, \mathrm{p}<.01, \mathrm{MSe}=121]$. For letter strings from "different" pairs, the word-nonword difference was not significant $[F(1,60)<1.0, \mathrm{MSe}=121]$.

Of particular importance in this experiment was the evidence that the case-change effect was not larger for the nonwords than for the words. If anything, results were in the opposite direction. The interaction between stimulus type (word-nonword) and case (old-new) was not significant $[F(1,30)<1.0, \mathrm{MSe}=130]$, even when the analysis was restricted to letter strings from "same" pairs $[F(1,30)<1.0, \mathrm{MSe}=168]$. Similar results were obtained when the set of letter strings (from "same" pairs) rather than subjects was used as the random variable in the analysis of variance. The word-nonword difference was significant $[F(1,19)=5.92, p<.05$, $\mathrm{MSe}=348]$, as was the old-case vs. new-case difference $[\mathrm{F}(1,19)=11.48, \mathrm{p}<.005, \mathrm{MSe}=111]$, but the WordNonword by Case (old vs. new) interaction was not significant $[\mathrm{F}(1,19)<1.0, \mathrm{MSe}=116]$. The failure to obtain a Word-Nonword by Case interaction was thus generalizable over both the subjects and the materials used in the experiment. Finally, an examination of the nonwords from "same" pairs indicated that there were only minor differences in recognition performance between the nonwords classified as orthographically regular and the nonwords classified as orthographically irregular.

\section{Discussion}

Phase 1 of this experiment involved an imagery task that directed subjects' attention to the graphemic characteristics of the letter strings. The Phase 2 recognition test indicated that words appearing in "same" pure-case pairs were recognized more accurately than words appearing in "same" mixed-case pairs. This verified the evidence, obtained in Experiment 1, that graphemic similarity could influence word recognition. In addition, 
the effect of case change obtained for the words was similar in magnitude to that obtained for the nonwords. This supported the conclusion that the absence of a graphemic effect on word recognition in Experiment 2 was a function of the phonemic processing required in Phase 1 of that experiment, not of differences in graphemic distinctiveness between the words and nonwords.

Nonwords were again recognized more accurately than words, even though comparable levels of graphemic retention were obtained for both. It could be concluded, in conjunction with the results of Experiment 2, that the word-nonword difference in recognition accuracy was due only in part to differences in graphemic retention between words and nonwords. It seems that, in addition to graphemic factors, the novelty or semantic distinctiveness of the nonwords contributes to their being recognized more accurately than the words. A similar conclusion has been reached by Lee, Tzeng, Garro, and Hung (1978) to explain a similar phenomenon: the superior recognition of rare words compared with common words.

As in the previous two experiments, letter strings from "different" pairs were recognized at a better-thanchance rate. It remained difficult, however, to determine the nature of the memory representations underlying this better-than-chance performance because the letter strings from "different" pairs tended to be insensitive to the experimental manipulations that produced significant effects for the letter strings from "same" pairs. Since the results of the three experiments provided no indication of a graphemic influence on the recognition of letter strings from "different" pairs, the strongest claim that could be made was that there was little retention of graphemic representations for these letter strings. Graphemic repetition, which is inherent in pure-case "sames" but not "differents," appears to be a necessary condition for obtaining graphemic effects on recognition accuracy in the present paradigm. Also, a word-nonword difference in recognition accuracy for items from "different" pairs was obtained only in Experiment 2. This may have been because only in Experiment 2 was semantic information retrieved for the words appearing in "different" pairs. Lexical access and the retrieval of semantic information may have been precluded in Experiment 1 as a result of "different" pairs being compared on a letter-by-letter basis and in Experiment 3 as a result of the difficulty of forming visual images for pairs of graphemically nonidentical letter strings. As indicated previously, there were no additional data that had any bearing on these conjectures for letter strings from "different" pairs.

\section{CONCLUSION}

Evidence of visual/graphemic effects on the recognition of previously seen words was obtained in Experiment 1 , which required the same-different comparison of letter strings during Phase 1, and Experiment 3, which required attention to graphemic representations of the letter strings during Phase 1. The graphemic effects in both these experiments involved differences in Phase 2 recognition accuracy between words from graphemically identical, pure-case "same" pairs and words from graphemically nonidentical, mixed-case "same" pairs. Further evidence for the retention of graphemic representations of words was obtained in Experiment 3. Words presented in their Phase 1 case during the Phase 2 recognition test were recognized more accurately than words whose case changed.

Experiment 2, which explicitly required the formation of phonemic representations of the letter strings during Phase 1, provided no evidence of a graphemic effect on the subsequent recognition of the words. That is, there was no difference in recognition accuracy between words from pure-case and mixed-case "same" pairs and no effect of changing the case of the words on the accuracy of their recognition. The significant effect of case change that was obtained for nonwords showed that the results for the words were not due to selective attention to the phonemic representations of letter strings required by the Phase 1 pronunciation task. Furthermore, graphemic effects were obtained when items classified as orthographically irregular were excluded from the analysis of the nonwords. It could be concluded, therefore, that the difference in graphemic retention between words and nonwords was due to the differential consequences of the presence or absence of a lexical entry for the items when phonemic representation was required. Finally, Experiment 3 ruled out differences in graphemic distinctiveness as a factor in the difference in graphemic retention between words and nonwords.

The results of the study were consistent with the hypothesis that translation from a graphemic to a phonemic medium would reduce subjects' ability to retrieve, from memory, the graphemic representations from which the phonemic representations of words are generated. That is, the results suggest, in accord with a sequential stage model, that the phonemic representation "displaces" in memory the graphemic representation from which it is derived. A factor that complicates the issue, however, is the considerable evidence that word processing is not purely sequential. At some point, depending on the particular model involved, parallel graphemic and phonemic channels emerge. For example, LaBerge and Samuels' (1974) model suggests that the graphemic representations from which phonemic representations can be generated (via the application of grapheme-to-phoneme translation rules to letters or spelling units) can also enter into a parallel channel in which lexical entries can be accessed graphemically. Another possibility (suggested by Baron, 1977) is that operating in parallel with a channel in which phonemic representations are generated (via the application of grapheme-to-phoneme translation rules to letters or spelling units) is a whole-word graphemic channel. For 
either model, graphemically mediated lexical access could result in the postlexical retrieval of the phonemic representation of the words. Although the "displacement" hypothesis might satisfactorily explain why there is minimal graphemic retention following the formation of a phonemic representation in one channel, it cannot in itself explain why there is no retention of the graphemic representation held in the parallel channel. If parallel processing models of the type described above are indeed valid, the results of the present study suggest that the ability to retrieve graphemic representations from memory is influenced by interactive relations between the channels. That is, the generation of a phonemic representation in one channel could result in the inhibition of attention to the graphemic representations held in either channel. Furthermore, the evidence that graphemic representations are retained for orthographically regular nonwords points to a postlexical locus for the inhibitory effect that phonemic processing seems to have on the retrieval of graphemic representation for words.

Finally, the results of this study complement those of Kolers (e.g., 1976). Kolers found relatively little influence of graphemic representations of previously read sentences on their subsequent recognition. Presumably, this was the case because the sentences were composed of words, not nonwords, and reading them involved translating the printed words into a phonemic representation. Kolers, however, did obtain evidence that graphemic representations facilitated the speed with which subjects reread previously read sentences. He argued, on this basis, for the retention of "pattern. analyzing operations" rather than the pictorial retention of the graphemic information in the words themselves. Another way of approaching this distinction is that graphemic representations of previously read words can facilitate early stages of graphemic processing when previously seen words are reread (in Scarborough et al.'s, 1977, lexical decision task, as well as Kolers' reading task). However, inhibitory effects due to phonemic processing can render the graphemic representations of the reread words unavailable during the postlexical stages of processing at which recognition ("I saw it during the previous phase of the experiment") might take place.

\section{REFERENCES}

Baddeley, A, D. The trouble with levels: A reexamination of Craik and Lockhart's framework for memory research. Psy. chological Review, 1978, 85, 139-152.

BAron, J. Mechanisms for pronouncing printed words: Use and acquisition. In D. LaBerge \& S. J. Samuels (Eds.), Basic processes in reading: Perception and comprehension. New York: Wiley, 1977.

Baron, J. The word-superiority effect: Perceptual learning from reading. In W. K. Estes (Ed.), Handbook of learning and cognitive processes (Vol. 6): Linguistic functions in cognitive theory. New York: Wiley, 1978.
Baron, J., \& Strawson, C. Use of orthographic and wordspecific knowledge in reading words aloud. Journal of Experimental Psychology: Human Perception and Performance, 1976, 2, 386-393.

Barron, R. W., \& Prttingen, J. B. The effect of orthographic structure and lexical meaning on "same"-"different" judgments. Quarterly Journal of Experimental Psychology, 1974, 26, 566-581.

Craik, F. I. M., \& Lockhart, R. S. Levels of processing: A framework for memory research. Journal of Verbal Learning \& Verbal Behavior, 1972, 11, 671-684.

Craik, F. I. M., \& Tulving, E. Depth of processing and the retention of words in episodic memory. Journal of Experimental Psychology: General, 1975, 104, 268-294.

Eysenck, M.W. Levels of processing: A critique. British Journal of Psychology, 1978, 69, 157-169.

Hock, H. S., Romanski, L., Galie, A., \& Williams, C. S. Real-world schemata and scene recogniton in adults and children. Memory \& Cognition, 1978, 6, 423-431.

Hunt, R. R., \& Elliotr, J. M. The role of nonsemantic information in memory: Orthographic distinctiveness effects on retention. Journal of Experimental Psychology: General, 1980, 109, 49-74.

KIRSNER, K. An analysis of the visual component in recognition memory for verbal stimulj. Memory \& Cognition, 1973, 1 , 449-453.

Kolers, P. A. Remernbering operations. Memory \& Cognition, 1973, 1, 347-355.

Kole rs, P. A. Two kinds of recognition. Canadian Journal of Psychology, 1974, 28, 51-60.

Kolers, P. A. Memorial consequences of automatized encoding. Journal of Experimental Psychology: Human Learning and Memory, 1975, 1, 689.701.

Kolers, P. A. Pattern-analyzing memory. Science, 1976, 191, 1280-1281.

Kolers, P. A., \& Ostry, D. J. Time course of loss of information regarding pattern analyzing operations. Journal of Verbal Learning and Verbal Behavior, 1974, 13, 599-612.

LaBenge, D., \& Samuels, J. Toward a theory of automatic information processing in reading. Cognitive Psychology, 1974, 6, 293-323.

Lee, A. T., Tzeng, O., Garho, L. C., \& Hung, D. L. Sensory modality and the word frequency effect. Memory \& Cognition, 1978, 6, 306-311.

Light, L. L., \& Berger, D. E. Are there long-term "literal copies" of visually presented words? Journal of Experimental Psychology: Human Learning and Memory, 1976, 2, 654-662.

Mayznen, M. S., \& Tresselt, M. E. Tables of single letter and digram frequency counts for various word-length and letterposition combinations. Psychonomic Monograph Supplements, 1965, 1(Whole No. 2), 13-78.

Meyer, D. E., Schvaneveldt, R. W., \& Ruddy, M. G. Functions of graphemic and phonemic codes in visual word recognition. Memory \& Cognition, 1974, 2, 309-321.

Morris, C. D., Bransford, J. D., \& Franks, J. J. Levels of processing versus transfer appropriate processing. Journal of Verbal Learning and Verbal Behaivor, 1977, 16, 519.533.

Pollatsek, A., Wel.l, A. D., \& Schindler, R. M. Familiarity affects visual processing of words. Journal of Experimental Psychology: Human Perception and Performance, 1975, 1, 328-338.

Scarborough, D. L., Cortese, C., \& Scarborough, H. S. Frequency and repetition effects in lexical memory. Journal of Experimental Psychology: Human Perception and Performance, $1977,3,1-17$.

Shulman, H. G., Hornak, R., \& Sanders, S. The effects of graphemic, phonetic, and semantic relationships on access to lexical structures. Memory \& Cognition, 1978, 6, 115-123.

ZeCHME ISTER, E. B. Orthographic distinctiveness as a variable in word recognition. American Journal of Psychology, 1972, 85, $425-430$. 


\section{NOTES}

1. It was not realized until the conclusion of the three experiments reported in this paper that, unlike all the "original" nonwords, 6 of the 60 nonword "distractors" were not derivable from common words by permuting the order of their letters (e.g., gawi). It was conceivable, therefore, that subjects could have used "derivability from common words" as a criterion in discriminating these "distractors" from the "original" nonwords with which they were paired. An examination of the data for all three experiments, however, indicated that recognition performance for these items had virtually no influence on the overall recognition accuracy that was obtained for the nonwords.

2. The nonwords from "same" pairs that were classified as orthographically irregular were: koob, stro, reba, emoh, esor, nepo, toda, raif, nera, torf, and lisk. This determination was based on an analysis of the frequency of occurrence in the English language for the first two, last two, and middle two digrams of each nonword. Nonwords were classified as irregular if the frequency was less than 10 for digrams appearing in the first two, last two, or "inner" two letter positions of fourto seven-letter words in a 20,000-word sample (Mayzner \& Tresselt, 1965).

3. An insightful reviewer has correctly pointed out that graphemic repetition could facilitate the strength of the memory trace, but the memory trace that is facilitated may not itself be graphemic. The results reported in Experiment 3 indicate, however, that the difference in recognition accuracy between words from pure-case and mixed-case "same" pairs can be attributed to differences between them in the retention of graphemic representations.

4. Half the subjects in this experiment read the letter strings silently, and half read them aloud. An examination of the data for the covert and overt readers indicated similar patterns of performance in the pronounceability rating task and the subsequent recognition test.

5. Excluded from the final data tabulation and analysis of variance were the recognition scores for three "different" pairs. These items were incorrectly typed on the recognition testing sheets. Included in the analysis of variance was a betweengroups variable involving the counterbalancing of items whose Phase 1 case remained the same and the items whose Phase 1 case was changed in the Phase 2 recognition test. The only significant effect associated with this variable was its interaction with the old-case vs. new-case variable (the same was true in Experiment 3). This interaction reflected differences in difficulty that were introduced when the items were subdivided for purposes of the case-change manipulation.

6. In this analysis, each nonword was paired with the purecase word from which it was generated (by permuting word order). For this reason, stimulus type (word vs. nonword) was treated as a repeated-measures variable in the analysis of variance. The three nonwords alluded to in Footnote 5, and the words they were generated from, were excluded from this analysis.

Appendix A

Letter Strings Presented in Phase 1 ("Originals")

\begin{tabular}{llllll}
$\begin{array}{c}\text { Words in } \\
\text { Mixed-Case Pairs }\end{array}$ & \multicolumn{2}{c}{$\begin{array}{c}\text { Words in } \\
\text { Pure-Case Pairs }\end{array}$} & \multicolumn{2}{c}{$\begin{array}{c}\text { Nonwords in } \\
\text { Pure-Case Pairs }\end{array}$} \\
\hline MAIN & main & LIKE & LIKE & KILE & KILE \\
BABY baby & BOOK & BOOK & KOOB & KOOB \\
SOAP & soap & MUST & MUST & STUM & STUM \\
SICK & sick & SORT & SORT & STRO & STRO \\
NOTE & note & BEAR & BEAR & REBA & REBA \\
CAST & cast & LINK & LINK & NILK & NILK \\
MESS mess & HOME & HOME & EMOH & EMOH \\
MILE mile & ROSE & ROSE & ESOR & ESOR \\
DIAL dial & OVER & OVER & ORVE & ORVE \\
BILL bill & OPEN & OPEN & NEPO & NEPO
\end{tabular}

\begin{tabular}{|c|c|c|c|c|c|}
\hline jump & JUMP & clip & clip & plic & plic \\
\hline also & ALSO & love & love & vole & vole \\
\hline wing & WING & toad & toad & toda & toda \\
\hline coat & COAT & fair & fair & raif & raif \\
\hline pill & PILL & cane & cane & nace & nace \\
\hline slow & SLOW & near & near & nera & nera \\
\hline duck & DUCK & fort & fort & torf & torf \\
\hline mast & MAST & pure & pure & prue & prue \\
\hline mind & MIND & silk & silk & lisk & lisk \\
\hline next & NEXT & slip & slip & plis & plis \\
\hline PEAR & pain & MOVE & SAVE & MEVO & SEVA \\
\hline FISH & fast & PALE & GATE & LAPE & TAGE \\
\hline BEEN & beam & SLIM & SKIN & SMIL & SNIK \\
\hline KILL & toll & MILK & MELT & KILM & TELM \\
\hline SHED & slid & GONE & PINE & NOGE & NIPE \\
\hline KIND & band & NONE & SOME & ENON & EMOS \\
\hline LOAD & lost & SALE & CAKE & LASE & KACE \\
\hline PORT & pond & TIME & LINE & METI & NELI \\
\hline LARK & tack & PINT & PEST & NIPT & SEPT \\
\hline VAST & wart & LOSS & LENS & SLOS & SLEN \\
\hline yell & YOLK & rust & vest & stur & stev \\
\hline tall & TOLD & curb & cork & crub & crok \\
\hline sane & MINE & sink & sand & kins & dans \\
\hline wear & WIRE & coal & crab & loac & brac \\
\hline rang & MANY & hope & tape & hepo & tepa \\
\hline ball & BELT & foul & tool & lufo & loto \\
\hline pull & GALL & tray & trip & yart & pirt \\
\hline pray & GRAY & card & bird & drac & drib \\
\hline fold & FIND & tone & bore & ento & ebro \\
\hline stay & SLAG & root & cool & orto & olco \\
\hline
\end{tabular}

Appendix B

"Distractor" Letter Strings Presented Along With "Originals" in Phase 2 Recognition Test

\begin{tabular}{llllll}
\hline \begin{tabular}{c} 
Paired With Mixed- \\
\multicolumn{2}{c}{ Case Words }
\end{tabular} & \multicolumn{2}{c}{ Paired With Pure- } & \multicolumn{2}{c}{ Paired With Pure- } \\
Case Words & \multicolumn{2}{c}{ Case Nonwords } \\
\hline TURN & arch & KNEE & into & ENKE & onti \\
SHOT & twin & DOVE & year & EVOD & aeyr \\
SWIM & town & WAIT & soul & ITAW & solc \\
CUTE & soft & VILE & born & VELI & norb \\
TIDE & form & HARD & news & DAHR & wens \\
RARE & past & SEEK & gain & EASK & gawi \\
IDEA & mass & THUS & mark & SUHT & karm \\
JOIN & pink & FELT & deep & TELF & eped \\
PART & pace & CLUE & zero & CELU & rezo \\
ROCK & suit & AREA & sing & AERA & gins \\
BULL & zinc & WIFE & mood & WEFI & odom \\
KISS & rain & TINY & gold & NITY & glod \\
DIET & golf & WIDE & raid & WEDI & diar \\
VERY & yawn & PLUG & talk & GLUD & kalt \\
FROM & club & NICE & stun & CINE & snut \\
ROLE & spot & PLOT & look & TOLP & kolo \\
ARMY & back & WENT & able & NEWT & elba \\
BOMB & snap & COIL & clad & ILCO & dalc \\
CENT & hunt & LAMP & tour & MALP & ruto \\
WEAK & tree & DIVE & evil & EPIV & nefi \\
REAL & rear & ARID & keen & ADIR & enek \\
RICE & away & LONG & film & NOLG & flim \\
RAPE & said & DONE & drip & DENO & prid \\
SPIT & salt & FIRM & host & MIRF & tosh \\
LAND & wish & DICE & meal & CIDE & mela \\
BRAT & risk & ZONE & boat & ENOZ & tabo \\
POEM & bust & TYPE & seen & PYTE & wees \\
CORN & lust & RACE & dark & CERA & krad \\
PEAL & peak & IRON & late & ORIW & elta \\
POOL & fade & LAME & male & ELAM & lema \\
\hline & & & & & \\
& & & & & \\
\hline
\end{tabular}

(Received for publication November 14, 1980; revision accepted February 23, 1981.) 